\title{
TAXONOMIC NOTES ON THE ANT, CAMPONOTUS COOPERI GREGG
}

\author{
By Robert E. GREgG \\ Department of Biology, University of Colorado
}

Several years ago I described an unusual Central American ant, naming it cooperi and placing it in the genus Camponotus (Gregg, 1951). The specimen, a single alate female, was sent to me by Dr. W. L. Brown, for description and illustration, together with some comments on its affinities. Since the facies of the ant is astonishingly like those of Camponotus, and particularly because of its close similarity to members of the subgenus Myrmostenus, both of us concluded it belonged to these groups. It was accordingly placed in the genus Camponotus and as a new species in the above subgenus which Emery had erected in 1920 to contain several South American species previously described by him. Unfortunately, all of these ants are known only from the female caste, no workers having as yet been found (Emery, 1925).

Recently, Dr. Brown checked the type of cooperi, and it now develops that the ant cannot possibly be considered a form of Camponotus owing to the fact that the antennae are 10-segmented instead of having 12 articles characteristic of the above named genus. The description and figure also give 10 as the antennal joint number, so the mistake obviously lies in our interpretation of the relationships of cooperi. The slip is attributable to the amazing similarities in habitus (except smaller size) between the new ant and those in the subgenus Myrmostenus, which resemblances are probably to be regarded as the products of convergent evolution.

Dr. Brown has offered the following statement (in litt.) with respect to his current view on the matter. "Although the proventriculus has not been dissected out for examination, it appears very probable that this species [cooperi] 
really belongs in the vicinity of Myrmelachista, particularly of the subgenus Decamera Roger. The species described by Menozzi (1935) as Aphomomyrmex (Neaphomus) goetschi from Chile also falls close into this group, according to his characterization and Wheeler's key of 1922. The genera of the tribe Myrmelachistini appear to be in confusion, partly due to the unsatisfactory nature of the antennal club as a stable group character. A female of Myrmelachista (Decamera) paderewskii Forel in the Museum of Comparative Zoology is almost as large as the cooperi female, but is much less aberrant in many ways. At present it appears best to consider Menozzi's goetschi, with cooperi, as members of an independent genus bearing the name Neaphomus Menozzi."

There is no doubt that cooperi must be removed from (amponotus and placed in another, and more appropriate, genus, and it seems advisable to do so without involving any new generic names at this time, even though the group chosen may be shown subsequently to be an artificial assemblage. However, I do not concur with Dr. Brown's treatment quoted above, which would produce certain nomenclatural changes, but feel that in view of the unsatisfactory nature of the classification of the various species concerned, it is much safer to make as few shifts as possible, and to place the ant in question in the genus Aphomo myrmex into which group it falls with no difficulty according to Wheeler's key to the genera written in 1922. Wheeler expressly states that the females of this genus have 10-segmented antennae, and since no workers accompanied the specimen of cooperi, it is impossible to state what their antennal condition may be and we are forced to rely entirely upon the segment number of the female. Furthermore, while the genus Myrmelachista (subgenus Jecamera) possesses 10-jointed antennae, the genus as a whole has a differentiated club, which is absent from the cooperi female, the joints of same showing a gradual increase in thickness toward the tips of the antennae. And finally, I am informed by Dr. Creighton that females of the genus Myrmelachista he has seen look much like those of Iridomyrmex in general appearance (despite the difference in subfamily allocation), which would make those species 
decidedly unlike the cooperi female. ${ }^{1}$

Wheeler gives the distribution of Aphomomyrmex as Ethiopian and Myrmelachista as Neotropical, but this is no proof the former could not occur in the New World tropics, especially as the fauna of that region is far from exhaustively studied. Moreover, Menozzi (1935) described a Neotropical Aphomomyrmex nearly twenty years ago, so it is not unknown from this side of the Atlantic. And the genus which Dr. Brown proposes, Neaphomus, has been regarded as a subgenus of Aphomomyrmex.

In view of the above discussion, therefore, and particular$l y$ since we are as yet unable to associate the worker caste with the female of the species concerned, I submit the following correction, and the synonymy then should read:

Aphomomyrmex (Neaphomus) cooperi (Gregg), new combination for Camponotus (Myrmostenus) cooperi Gregg, 1951, loc. cit.

\section{Iitherature Cited}

Hamery, C.

1925. Subfam. Formicinae. Genera Insectorum, Fasc. 183.

Gregi, R. H.

1951. Two new species of exotic ants. Psyche, 58:77-84.

Menozz, C.

1935. Je Formiche del Cile. Zool. Jahrb. Syst., 67:319-336.

WhELLKR, W. M.

1922. Keys to the genera and subgenera of ants. Bull. Amer. Mus. Nat. Hist., 45:631-710.

\footnotetext{
'In contrast, Dr. Brown believes, "there is no essential differenes in the clavation of the antennae between cooperi and certain Decamera species. In fact, cooperi may be said to have stronger and more definite rlavation of the funiculi than does $M$. (D.) paderewskii female. Furtbermore, eertain species of Myrmelachisla (eg. M. skwarrae) art smaller replicas of $N$. goelschi in all essential habitus characters, including the lengthened head. Thus, while to Creighton some Myrmelachisla females may look like Iridomyrmex of the same caste . . ., at least som have an appearance very much different from that of Iridomyrmex."
} 

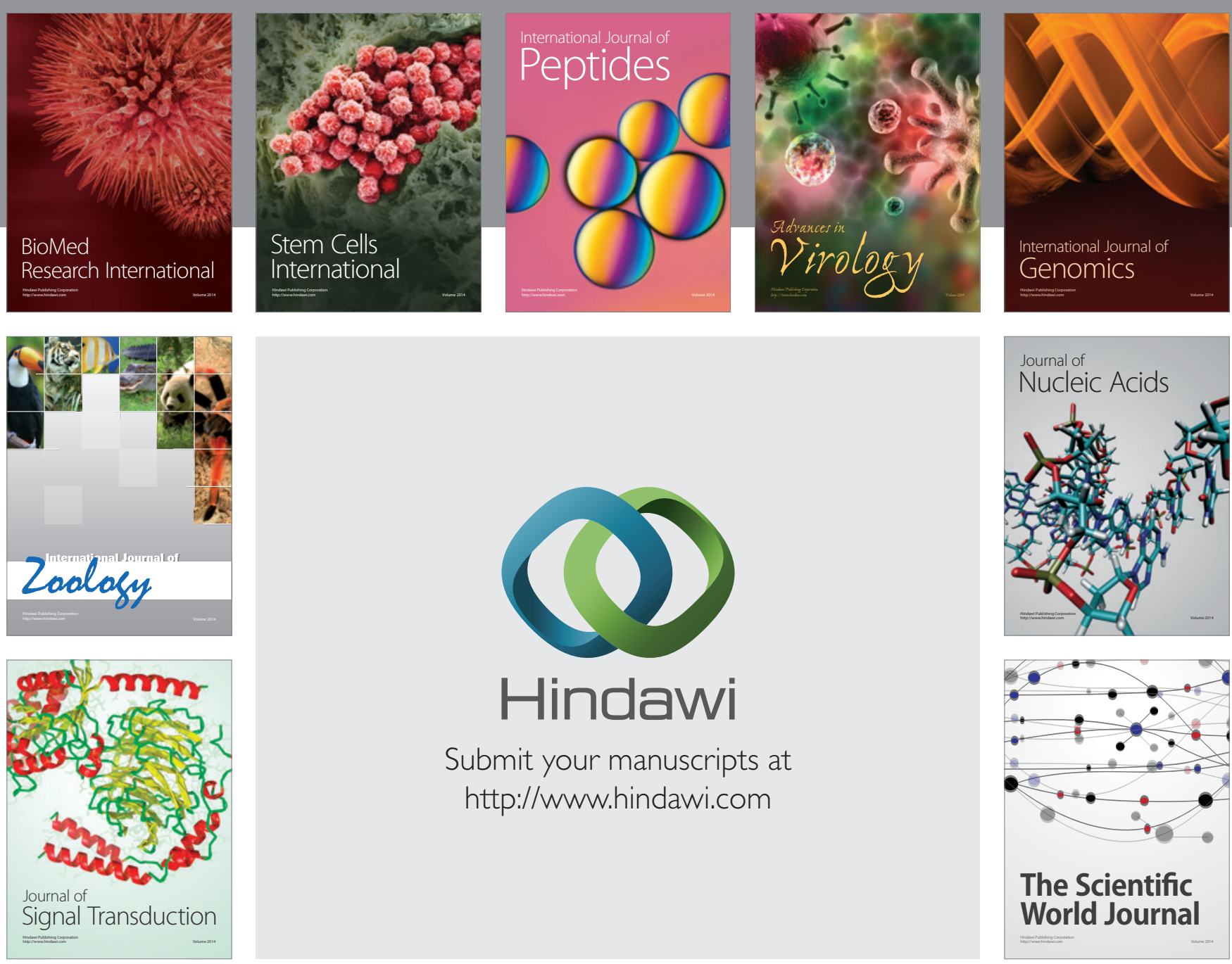

Submit your manuscripts at

http://www.hindawi.com
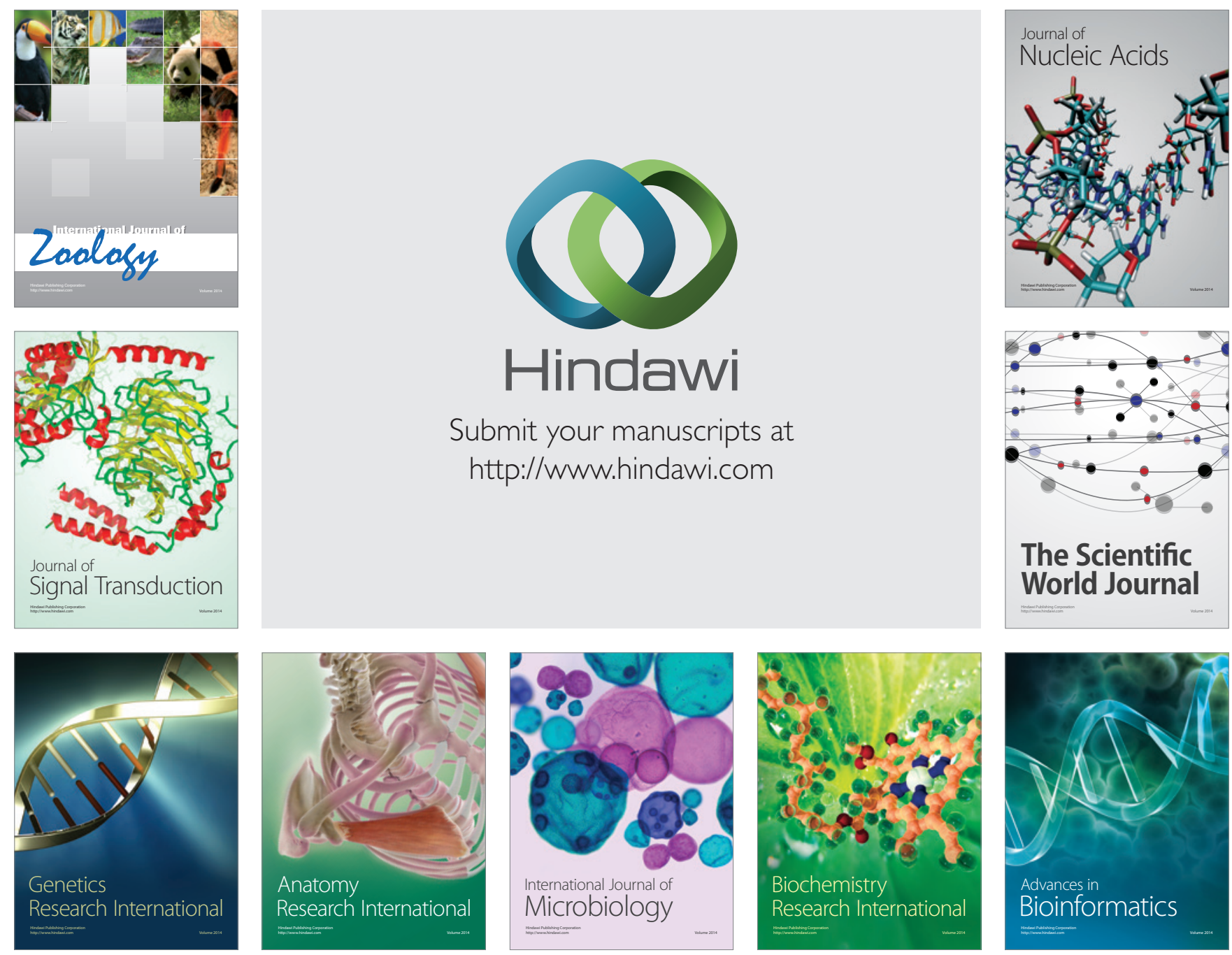

The Scientific World Journal
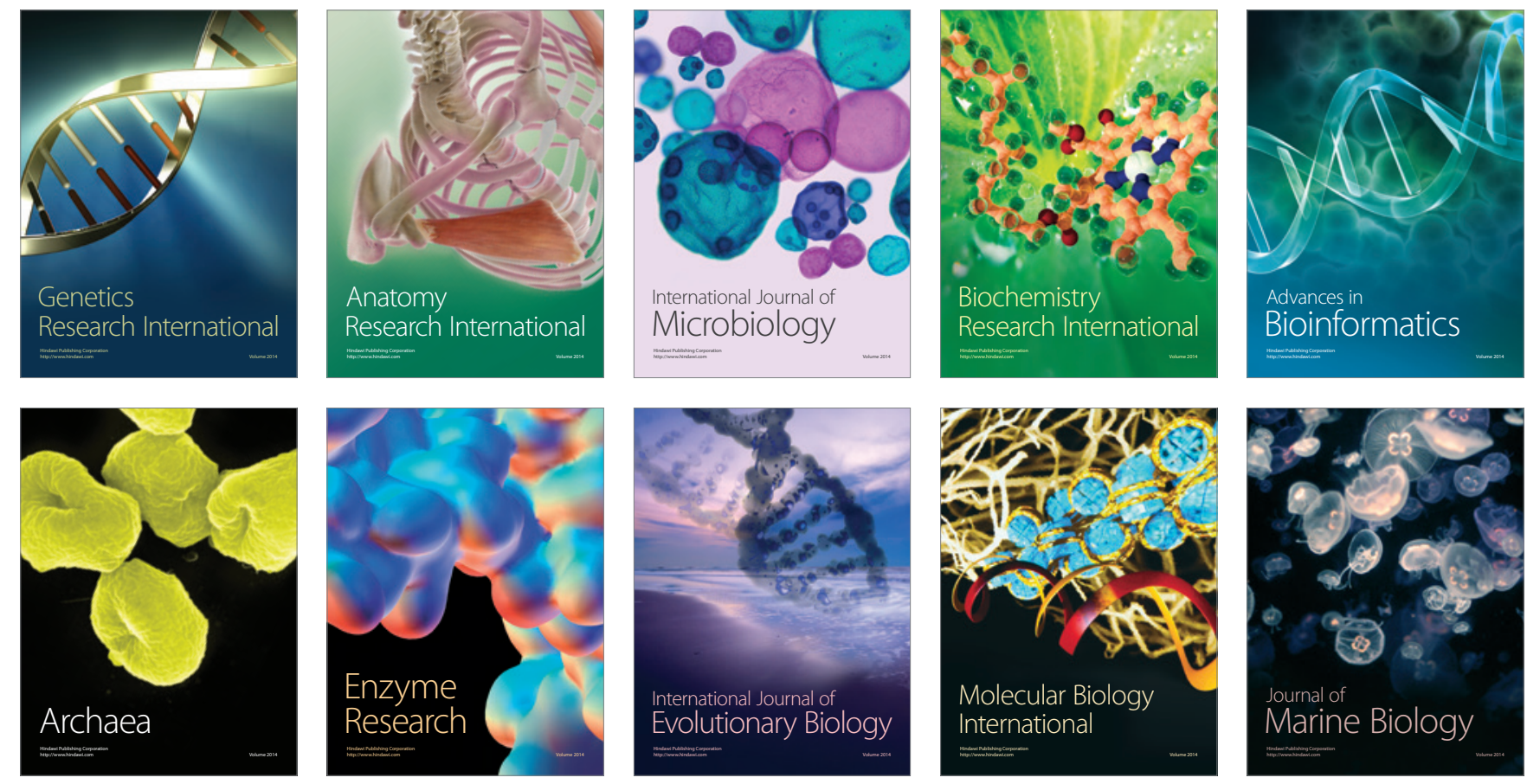